\title{
Takotsubo Cardiomyopathy in a Patient with Severe Hyponatremia Associated with Syndrome of Inappropriate Antidiuretic Hormone
}

\author{
Hiroaki Kawano $^{1}$, Yuji Matsumoto ${ }^{1}$, Shuji Arakawa ${ }^{1}$, Motonobu Hayano ${ }^{1}$ \\ and Hiroyuki Fijisawa ${ }^{2}$
}

\begin{abstract}
Although the etiology of Takotsubo cardiomyopathy (stress-induced cardiomyopathy) is unknown, there is a wide variability in the psychological and physical triggers for Takotsubo cardiomyopathy. We report here a case of Takotsubo cardiomyopathy associated with severe hyponatremia.
\end{abstract}

Key words: cardiomyopathy, hyponatremia, sodium

(Intern Med 50: 727-732, 2011)

(DOI: 10.2169/internalmedicine.50.4795)

\section{Introduction}

Takotsubo cardiomyopathy, or stress-induced cardiomyopathy, is characterized by reversible left ventricular apical ballooning associated with emotional or physiological stress, which mimics acute myocardial infarction in the absence of significant coronary artery disease at angiography (1-3). The precise mechanism of Takotsubo cardiomyopathy remains obscure, although its onset is triggered by acute illness or intense emotional or physical stress $(4,5)$. Some investigators have reported Takotsubo cardiomyopathy associated with hyponatremia (6-8). We report here a case of Takotsubo cardiomyopathy in severe hyponatremia associated with the syndrome of inappropriate antidiuretic hormone (SIADH).

\section{Case Report}

An 82-year-old Japanese man was undergoing regular follow-up by his family doctor for chronic alcoholism, epilepsy, and gastrectomy performed for gastric cancer. He had been admitted to our hospital because of Mallory-Weiss syndrome and hyponatremia approximately 6 months previously. At that time, based on his test data, he was diagnosed with SIADH; serum sodium level, $110 \mathrm{mEq} / \mathrm{L}$; serum osmo- lality, $240 \mathrm{mOsm} / \mathrm{kg}$; urine osmolality, $518 \mathrm{mOsm} / \mathrm{kg}$; urine sodium level, $87 \mathrm{mEq} / \mathrm{L}$; arginine vasopressin, $0.6 \mathrm{pg} / \mathrm{mL}$. His electrocardiogram (ECG) was normal (Fig. 1A) and he had no signs or symptoms of heart failure or heart disease. Four days after treatment for hyponatremia with food and fluid restriction (total oral intake, $500 \mathrm{~mL}$ per day) and saline infusion $(500 \mathrm{~mL} /$ day $)$, his serum sodium level was increased from $110 \mathrm{mEq} / \mathrm{L}$ to $122 \mathrm{mEq} / \mathrm{L}$, and saline infusion was stopped and food intake was gradually increased. He was discharged with a serum sodium level of $134 \mathrm{mEq} / \mathrm{L}$ about 2 weeks after admission.

After discharge, he was admitted to a psychiatric hospital for hallucinations and violent behavior. His medication profile included phenytoin, $200 \mathrm{mg}$; flunitrazepam, $1 \mathrm{mg}$; trazodone hydrochloride, $50 \mathrm{mg}$; famotidine, $20 \mathrm{mg}$, each once daily. About one month after admission to the psychiatric hospital, an echocardiography was performed in our hospital because of sinus bradycardia and it showed normal wall motion of left ventricle. Subsequently, he was transferred to our hospital following complaints of dyspnea and vomiting about three months after admission to the psychiatric hospital.

On examination, his heart rate was 80 beats/min and blood pressure was $90 / 60 \mathrm{mmHg}$. His consciousness level corresponded to Japan Coma Scale 100, and no apparent neurological deficit was observed. Although a brain CT and

${ }^{1}$ Department of Cardiology, Nagasaki Rosai Hospital, Japan and ${ }^{2}$ Department of Radiology, Nagasaki Rosai Hospital, Japan Received for publication November 5, 2010; Accepted for publication December 13, 2010 Correspondence to Dr. Hiroaki Kawano, hirokawa@na-robyo.jp 
A

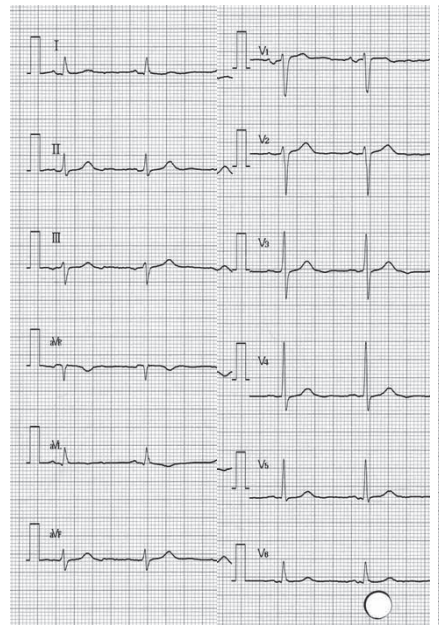

B

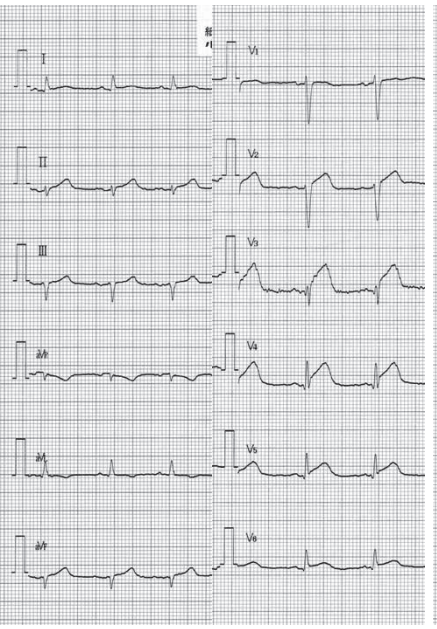

C

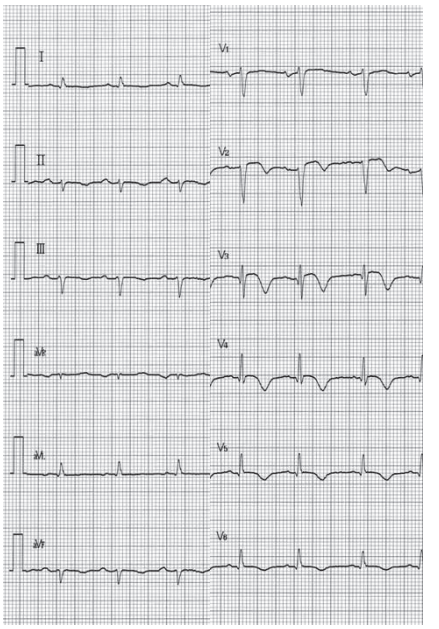

Figure 1. Electrocardiography (ECG) before and after admission. A: ECG on previous admission; ECG showed sinus rhythm, flat $T$ wave in ${ }_{a} V_{L}$. B: ECG on admission: ECG showed left axis deviation and ST-segment elevation in II, III, ${ }_{a} V_{F}$, and $V_{2-6 .}$ C: ECG on the day after admission: ECG showed negative $T$ wave in II, III, ${ }_{a} V_{F}$, and $V_{2-6}$.
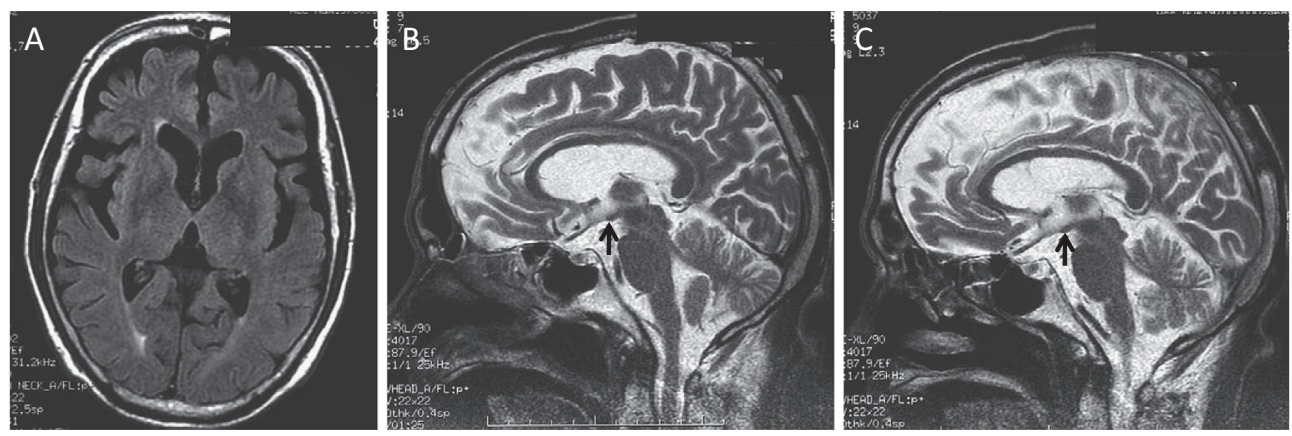

Figure 2. Brain computed tomography (CT) and magnetic resonance image (MRI) on admission. Brain CT showed no acute cerebral infarction and bleeding, and mild atrophy of bilateral anterior lobes was seen (A). Brain MRI showed mild atrophy of bilateral anterior lobes and severe atrophy of right (B) and left (C) bilateral mammillary bodies (arrows) were seen.

MRI showed no acute cerebral infarction or bleeding, mild atrophy of the bilateral anterior lobes and severe atrophy of bilateral mammillary bodies were observed (Fig. 2). His chest radiography showed no abnormal findings except for pleural calcification. The initial ECG showed a sinus rhythm and ST-segment elevation in V1-5 (Fig. 1B). His serum sodium level was $104 \mathrm{mEq} / \mathrm{L}$; uric acid, $2.2 \mathrm{mg} / \mathrm{dL}$; blood urea nitrogen, $7.4 \mathrm{mg} / \mathrm{dL}$; creatinine, $0.53 \mathrm{mg} / \mathrm{dL}$; serum osmolality, $246 \mathrm{mOsm} / \mathrm{kg}$; urinary osmolality, $169 \mathrm{mOsm} / \mathrm{kg}$; urinary sodium, $23 \mathrm{mEq} / \mathrm{L}$. The serum level of creatine kinase was normal but his serum cardiac troponin I was $2.193 \mathrm{ng} / \mathrm{mL}$ (normal, $<0.04 \mathrm{ng} / \mathrm{mL}$ ), and the serum level of brain natriuretic peptide (BNP) was $1025.6 \mathrm{pg} / \mathrm{mL}$ (Table 1); furthermore, laboratory data showed normal thyroid and adrenal function, but serum levels of norepinephrine and dopamine were increased (Table 1). His echocardiography showed akinesis of the left ventricular apex (Fig. 3A and B), and an emergent cardiac catheterization was performed. Coronary angiography showed no significant coronary stenosis, although left ventriculography demonstrated akinesis of the left ventricular apex (Fig. 4A, B). Based on these data, the patient was diagnosed with Takotsubo cardiomyopathy. He was immediately treated with intravenous saline infusion with total parenteral nutrition (total fluid of $1,500 \mathrm{~mL} /$ day and total $\mathrm{NaCl}$ infusion of $200 \mathrm{mEq} / \mathrm{day}$ ) to correct his serum sodium level with treatment for heart failure due to Takotsubo cardiomyopathy with intravenous infusion of $20 \mathrm{mg}$ furosemide per day, and a serum sodium level was increased as follows: $120 \mathrm{mEq} / \mathrm{L}, 2$ days after admission; $131 \mathrm{mEq} / \mathrm{L}, 5$ days after admission.

The following day, an ECG showed a negative $\mathrm{T}$ wave in V2-6 (Fig. 1C). His condition had improved, and two weeks after admission, echocardiography showed normal kinesis of the left ventricular apex (Fig. 3C, D). About 1 month after the admission, he was discharged with a serum sodium level of $136 \mathrm{mEq} / \mathrm{L}$ and a serum level of BNP of $135 \mathrm{pg} / \mathrm{mL}$. 
Table 1. Laboratory Data

\begin{tabular}{|c|c|c|c|}
\hline WBC: $6710 / \mu \mathrm{L}$ & Na: 105 mEq/L & ALP: 690 IU/L & BNP: $1025.6 \mathrm{pg} / \mathrm{mL}$ \\
\hline $\mathrm{RBC}: 310 \times 10^{4} / \mu \mathrm{L}$ & $\mathrm{K}: 4.7 \mathrm{mEq} / \mathrm{L}$ & $\gamma$-GTP: $81 \mathrm{IU} / \mathrm{L}$ & E: $0.02 \mathrm{ng} / \mathrm{mL}(0.0-0.1)$ \\
\hline $\mathrm{Hb}: 9.3 \mathrm{~g} / \mathrm{dL}$ & $\mathrm{Cl}: 78 \mathrm{mEq} / \mathrm{L}$ & CK: $60 \mathrm{IU} / \mathrm{L}$ & NE: $1.25 \mathrm{ng} / \mathrm{mL}(0.1-0.5)$ \\
\hline Het: $25.3 \%$ & $P: 2.3 \mathrm{mg} / \mathrm{dL}$ & CK-MB: IU/L & DA: $1.80 \mathrm{ng} / \mathrm{mL}(0.00-0.03)$ \\
\hline Plt: $5.8 \times 10^{4} / \mu \mathrm{L}$ & $\mathrm{Ca}: 6.9 \mathrm{mg} / \mathrm{dL}$ & AMY: $90 \mathrm{IU} / \mathrm{L}$ & Cortizol $20.8 \mathrm{mg} / \mathrm{dL}(4.5-21.1$ \\
\hline \multirow[t]{2}{*}{ PT (INR) 1.10} & BUN : 7.4 mg/dL & Ch-E: 157 IU/L & TSH: $1.0714 \mu \mathrm{IU}$ \\
\hline & Cre: $0.53 \mathrm{mg} / \mathrm{dL}$ & UA: $2.2 \mathrm{mg} / \mathrm{dL}$ & free T4: $1.07 \mathrm{ng} / \mathrm{dL}$ \\
\hline HBsAg(-) & $\mathrm{TP}: 4.9 \mathrm{~g} / \mathrm{dL}$ & Glu: $107 \mathrm{mg} / \mathrm{dL}$ & free T3: $0.63 \mathrm{pg} / \mathrm{mL}$ \\
\hline HCVAb(-) & Alb: $2.5 \mathrm{~g} / \mathrm{dL}$ & LDL-C: 76 mg/dL & Serum Osm 246 mOsm/kg \\
\hline ТPHA(-) & T bil $0.5: \mathrm{mg} / \mathrm{dL}$ & HDL-C: 48 mg/dL & Urine Osm $169 \mathrm{mOsm} / \mathrm{kg}$ \\
\hline \multirow[t]{3}{*}{ RPR (-) } & AST: $32 \mathrm{IU} / \mathrm{L}$ & TG: $49 \mathrm{mg} / \mathrm{dL}$ & Urine $\mathrm{Na} 23 \mathrm{mEq} / \mathrm{L}$ \\
\hline & ALT: 19 IU/L & CRP: $6.11 \mathrm{mg} / \mathrm{dL}$ & ADH $0.8 \mathrm{pg} / \mathrm{mL}(0.3-4.2)$ \\
\hline & LDH: 167 IU/L & Troponin I: $2.193 \mathrm{ng}$ & $\mathrm{nL}$ \\
\hline \multicolumn{4}{|c|}{ WBC, white blood cell count; RBC, red blood cell count; Hb, hemoglubin; PLT, platelet } \\
\hline \multicolumn{4}{|c|}{$\begin{array}{l}\text { BUN, blood urea nitrogen; } \mathrm{Cr} \text {, creatinine; } \mathrm{TP} \text {, total protein; Alb, albumin; } \mathrm{T} \text { bil, total bilirubin, } \\
\text { AST, aspartate aminotransferase; ALT, alanine aminotransferase }\end{array}$} \\
\hline \multicolumn{4}{|c|}{ LDH, lactate dehydrogenase; ALP, allkaline phosphatase, ; g-GTP, g-glutamyltransferase } \\
\hline \multicolumn{4}{|c|}{ CK, creatine kinase; AMY, amylase; Ch-E, cholinesterase; UA, uric acid } \\
\hline \multicolumn{4}{|c|}{ Glu, glucose; LDL-C, low-density lipoprotein cholesterol } \\
\hline \multicolumn{4}{|c|}{ HDL-C, high-density lipoprotein cholesterol; TG, triglyceride; CRP, c-reactive protein; } \\
\hline \multicolumn{4}{|c|}{ BNP, brain natriutetic peptide; E, epinephrine; NE, noepinephrine; DA, dopamine, } \\
\hline
\end{tabular}

\section{Discussion}

Hyponatremia is the most commonly observed electrolyte imbalance in hospitalized patients, and a majority of patients with hyponatremia are asymptomatic and do not require immediate correction $(9,10)$. In contrast, symptomatic hyponatremia is a medical emergency requiring rapid correction to prevent worsening of brain edema, and is associated with increased morbidity and mortality; however symptomatic hyponatremia is frequently under-recognized and untreated $(9,10)$. Only four cases have reported Takotsubo cardiomyopathy associated with hyponatremia without adrenal insufficiency and hypothyroidism (Table 2) (6-8). All of these cases had severe hyponatremia $(\mathrm{Na}<125 \mathrm{mEq} / \mathrm{L})$. Severe hyponatremia, if developing rapidly (within 48 hours), involves critical symptoms, such as confusion, unconsciousness, grand mal seizures, and even death. In the present case, Takotsubo cardiomyopathy occurred at the serum sodium level of $105 \mathrm{mEq} / \mathrm{L}$, although it did not occur at the serum sodium level of $110 \mathrm{mEq} / \mathrm{L}$ on previous admission. Thus, the severity of hyponatremia seems important for the occurrence of Takotsubo cardiomyopathy, although according to previous reports the threshold serum sodium levels at which it occurs may be different among patients (Table 2).

Two of these 4 published cases developed Takotsubo cardiomyopathy following a hyponatremic seizure $(6,7)$. Seizure is also associated with Takotsubo cardiomyopathy (11), and these studies suggest that seizure induces a catecholamine storm or sympathetic surge that provokes Takotsubo cardiomyopathy. The patient in this case had confusion without seizure at the time of present admission because he was on phenytoin medication for epilepsy. Thus, in the pre- sent case, seizure was not a direct trigger of Takotsubo cardiomyopathy. AbouEzzeddine and Prasad (8) reported 2 cases of Takotsubo cardiomyopathy triggered by hyponatremia without epilepsy. They suggested that Takotsubo cardiomyopathy occurred as a direct consequence of hyponatremia. In the present case, we demonstrated high serum levels of dopamine and norepinephrine. Although the precise mechanism of Takotsubo cardiomyopathy has not been determined, an acute catecholamine toxicity of the myocardium has been believed to be one of the causes (5). Norepinephrine is a sympathetic neurotransmitter and dopamine is its precursor. These facts suggest that excessive catecholamine release from sympathetic nerves may provoke Takotsubo cardiomyopathy with severe hyponatremia, although severe hyponatremia did not induce seizure. However, the mechanism of excessive catecholamine release by severe hyponatremia is still unknown.

There are several causes of hyponatremia and the most common causes in adults are therapy with thiazides, the postoperative state and other causes of SIADH, polydipsia in psychiatric patients, dehydration, hypothyroidism, adrenal insufficiency, and volume overload related to heart failure, nephritic syndrome, and cirrhosis (12). Considering the 4 previous reports, hyponatremia in Takotsubo cardiomyopathy was attributed to SIADH $(n=2)$, diuretics $(n=1)$, and unknown causes $(n=1)$.

Although the causes of SIADH are myriad, they include disorders of the central nervous system and antipsychotic or psychotropic drugs. Moreover, the 2 previously reported cases associated with SIADH had disorders of the central nervous system or psychiatric disorders, and the one previously reported case with unknown cause for hyponatremia had schizophrenia. This suggests that disorders of the central 

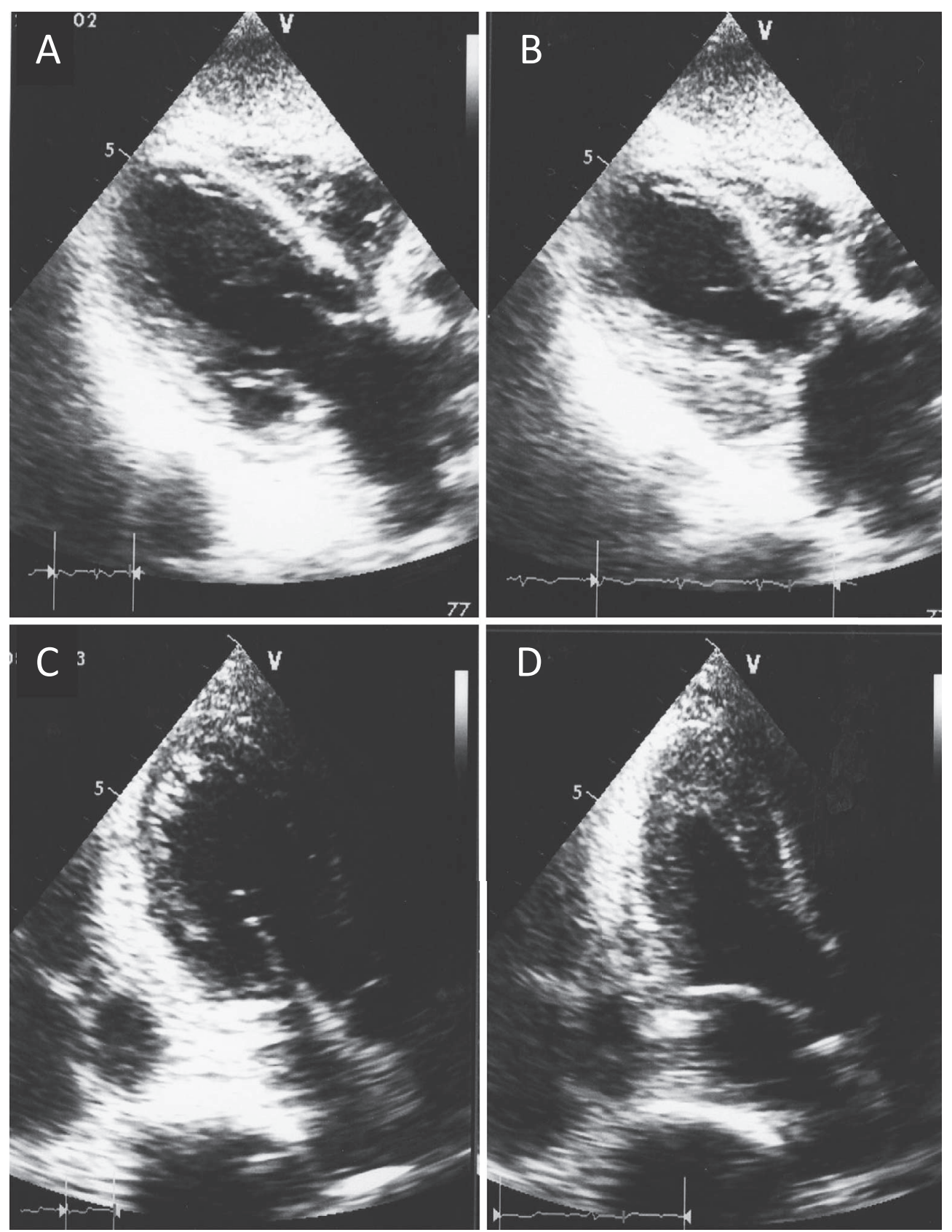

Figure 3. Echocardiography (UCG) on admission and about 2 weeks after admission. UCG demonstrated akinesis of apex of the left ventricle (A, end-diastolic phase; B, end-systolic phase) on admission and showed recovered apical wall motion of the left ventricle 2 weeks after admission (C, end-diastolic phase; D, end-systolic phase).

nervous system and/or psychiatric disorders, in addition to severe hyponatremia, play important roles in the catecholamine release.

In the present case, the patient was on antipsychotic drugs for chronic alcoholism. These antipsychotic drugs may have progressed the severity of hyponatremia which is related to Takotsubo cardiomyopathy. Furthermore, his MRI showed atrophy of the bilateral mammillary bodies with mild frontal lobe atrophy. Classically, acute thiamine deficiencyassociated Wernicke's encephalopathy (WE) is marked neuropathologically by lesions of periventricular nuclei, hypothalamic nuclei, tectal plate, and thalamus, which are caused by thiamine (vitamin B1) deficiency. Acute WE when left untreated or if treated incompletely with thiamine or too late can lead to profound, debilitating global amnesia that is a marker for Korsakoff syndrome. In this later phase, targeted structures, notably the mammillary bodies, become atrophic $(13,14)$. To date, only one report has demonstrated a relationship between SIADH and WE (15). Thus, Korsakoff syndrome may be related to the cause of SIADH and the mechanism of occurrence of Takotsubo cardiomyopathy with severe hyponatremia in the present case. Although the present case had two important factors for thiamine deficiency, i.e., chronic alcoholism and gastrectomy, we did not mea- 

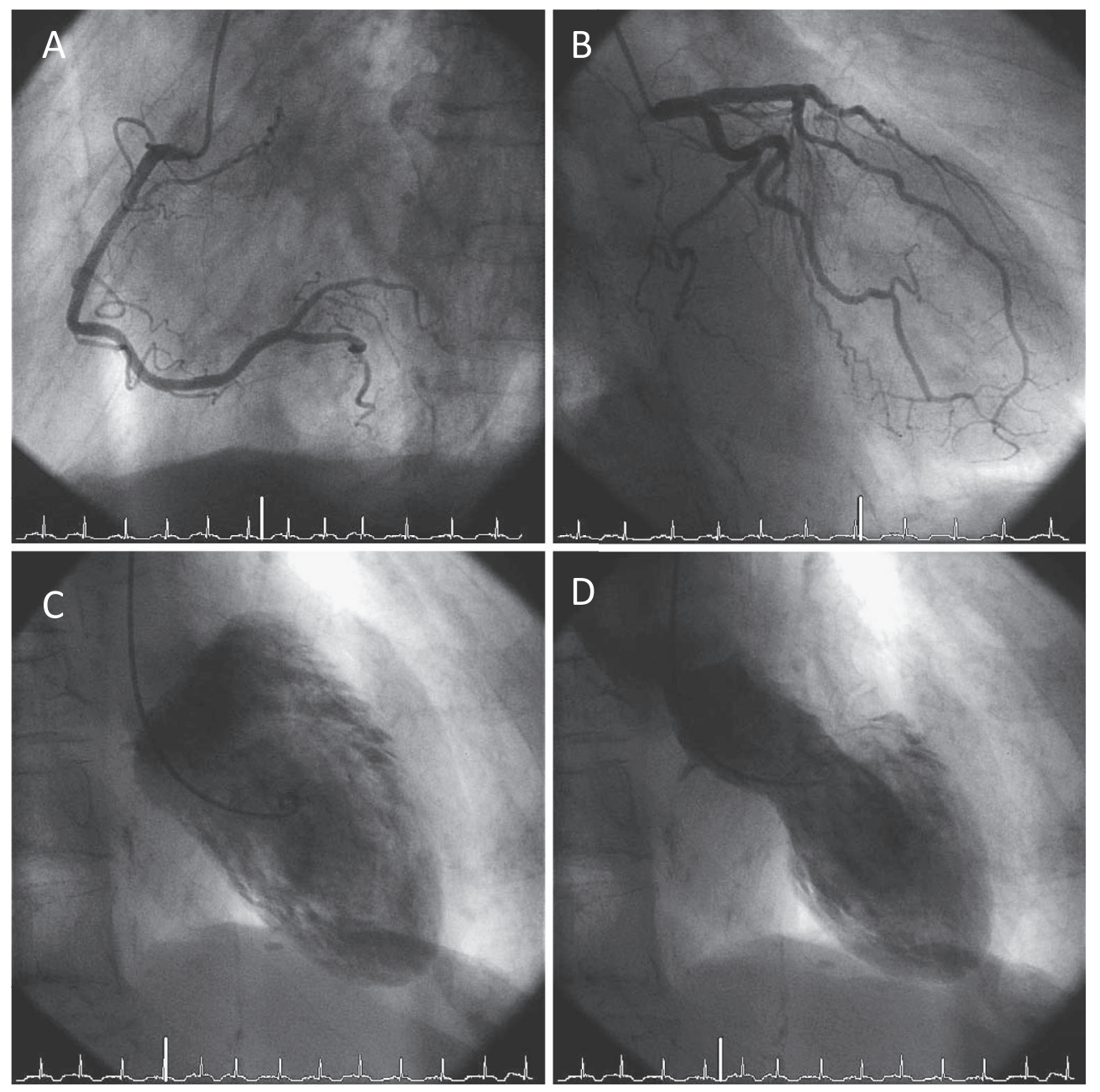

Figure 4. Coronary angiography (CAG) and Left ventriculography (LVG) on admission. CAG showed normal right (A) and left (B) coronary arteries. LVG demonstrated akinesis of the apex of the left ventricle $(\mathrm{C}$, end-diastolic phase; $\mathrm{D}$, end-systolic phase) on admission.

Table 2. Reports of Takotsubo Cardiomyopathy with Hyponatremia

\begin{tabular}{|c|c|c|c|c|c|c|c|}
\hline & Age & Sex & Disease & $\mathrm{Na}(\mathrm{mEq} / \mathrm{L})$ & Association with Seizure & Cause of Hyponatremia & Ref \\
\hline 1 & 69 & $\mathrm{~F}$ & multiple sclerosis & 109 & $\mathrm{Y}$ & SIADH & 6 \\
\hline 2 & 63 & $\mathrm{~F}$ & schizophrenia & 110 & $\mathrm{Y}$ & not determined & 7 \\
\hline 3 & 76 & $\mathrm{~F}$ & hypertension, diabetes & 120 & $\mathrm{~N}$ & Diuretics & 8 \\
\hline 4 & 57 & $\mathrm{~F}$ & bipolar disorder & 111 & $\mathrm{~N}$ & SIADH & 8 \\
\hline 5 & 82 & M & chronic alcoholism, epilepsy & 105 & $\mathrm{~N}$ & SIADH and Vomit & Our case \\
\hline
\end{tabular}

sure the thiamine level because the patient had a vitamin infusion immediately before he was transferred to our hospital. However, his psychiatric problems improved and serum sodium level was easily maintained at a normal level after treatment with thiamine in addition to the sodium supplementation.

In the present case, admission to a psychiatric hospital did not seem to be a major trigger for occurrence of Takotsubo cardiomyopathy although it may influence it in part because echocardiography showed normal wall motion of the left ventricle about one month after admission to the psychiatric hospital, and there was no episode as a stress event for him before the occurrence of Takotsubo cardiomyopathy. More- over, we have no evidence of Korsakoff syndrome itself as a trigger for the induction of Takotsubo cardiomyopathy, and there is no report on it to date. Further study seems necessary to evaluate this possibility.

In conclusion, we should consider the importance of severe hyponatremia as a stressor for Takotsubo cardiomyopathy, especially in association with diseases of the central nervous system and/or psychiatric disorder.

The authors state that they have no Conflict of Interest (COI). 


\section{References}

1. Tsuchihashi K, Ueshima K, Uchida $\mathrm{T}$, et al; Angina PectorisMyocardial Infarction Investigations in Japan. Transient left ventricular apical ballooning without coronary artery stenosis: a novel heart syndrome mimicking acute myocardial infarction. J Am Coll Cardiol 38: 11-18, 2001.

2. Kurisu S, Sato H, Kawagoe T, et al. Tako-tsubo-like left ventricular dysfunction with ST-segment elevation: a novel cardiac syndrome mimicking acute myocardial infarction. Am Heart J 143: 448-455, 2002.

3. Abe Y, Kondo M, Matsuoka R, Araki M, Dohyama K, Tanio H. Assessment of clinical features in transient left ventricular apical ballooning. J Am Coll Cardiol 41: 737-742, 2003.

4. Sharkey SW, Lesser JR, Zenovich AG, et al. Acute and reversible cardiomyopathy provoked by stress in women from the United States. Circulation 111: 472-479, 2005.

5. Wittstein IS, Thiemann DR, Lima JA, et al. Neurohumoral features of myocardial stunning due to sudden emotional stress. N Engl J Med 352: 539-548, 2005.

6. Worthley MI, Anderson TJ. Transient left ventricular apical ballooning syndrome following a hyponatraemic seizure. Int $\mathrm{J}$ Cardiol 115: e102-e104, 2007.

7. Lemke DM, Hussain SI, Wolfe TJ, et al. Takotsubo cardiomyopa- thy associated with seizures. Neurocrit Care 9: 112-117, 2008.

8. AbouEzzeddine O, Prasad A. Apical ballooning syndrome precipitated by hyponatremia. Int J Cardiol 145: e26-e29, 2010.

9. Hoorn EJ, Halperin ML, Zietse R. Diagnostic approach to a patient with hyponatremia: traditional versus physiology-based options. QJM 98: 529-540, 2005.

10. Lien YH, Shapiro JI. Hyponatremia: clinical diagnosis and management. Am J Med 120: 653-658, 2007.

11. Sakuragi S, Tokunaga N, Okawa K, Kakishita M, Ohe T. A case of takotsubo cardiomyopathy associated with epileptic seizure: reversible left ventricular wall motion abnormality and ST-segment elevation. Heart Vessels 22: 59-63, 2007.

12. Upadhyay A, Jaber BL, Madias NE. Epidemiology of hyponatremia. Semin Nephrol 29: 227-238, 2009.

13. Charness ME, DeLaPaz RL. Mammillary body atrophy in Wernicke's encephalopathy: antemortem identification using magnetic resonance imaging. Ann Neurol 22: 595-600, 1987.

14. Sheedy D, Lara A, Garrick T, Harper C. Size of mamillary bodies in health and disease: useful measurements in neuroradiological diagnosis of Wernicke's encephalopathy. Alcohol Clin Exp Res 23: 1624-1628, 1999.

15. Cooles PE, Borthwick LJ. Inappropriate antidiuretic hormone secretion in Wernicke's encephalopathy. Postgrad Med J 58: 173174, 1982.

(C) 2011 The Japanese Society of Internal Medicine http://www.naika.or.jp/imindex.html 